\section{From the Editor's desk}

By Peter Tyrer

\section{Securing the strands of schizophrenia safely}

When I first joined the editorial board of the British Journal of Psychiatry in 1975 the then editor, Edward Hare, often had articles linked together in groups with a common theme. One of my first contributions was to express my concern that some authors may be disadvantaged by this procedure as they could have the publication of their articles delayed unfairly. This rather unctuous remark was taken seriously and the system was abandoned shortly afterwards. What has impressed me over the subsequent years of essentially consecutive publications is how many still seem to come together naturally. Schizophrenia, whether you hate it for its pervading ubiquity or embrace its manifold ability to accommodate so much pathology, is nicely set up in this issue. Eugen Bleuler, in his first elegant description of schizophrenia, ${ }^{1}$ frequently used the analogy of an unravelled rope to illustrate the inefficiency of the disintegrated brain, and ever since we seem, like manic seamstresses, to be rushing around trying to tie anarchic strands to the main rope again; but each success is followed by yet another filament breaking off and challenging us defiantly to be tamed.

We have never quite been able to resolve the paradox of treatment in schizophrenia: the archetypal severe mental disorder seemingly crying out for help. If psychiatrists are worth their salt, they should be able to treat this brain disease, but despite the many structural abnormalities identified since the breakthrough by Johnstone and her colleagues in $1976,{ }^{2}$ the latest chapter being the fascinating paper by Walterfang et al (pp. 429-434) suggesting differences in the corpus callosum between early and late stages of the condition, we have never been entirely confident that tackling this brain pathology with drugs is the only correct way forward. The problem is that so many people either do not respond to our treatment, want to avoid it entirely, or are so handicapped by adverse effects that the benefits disappear. We then enter the field of alleged 'treatment resistance', a relatively modern concept which Berrios $(2008, \text { p. } 18)^{3}$ has described as part of a 'mercantile transaction' in which 'like the selling of faulty goods, "lack of response" is increasingly being considered as a violation of a putative trade descriptions act'. So in the court of public opinion we are often accused of misleadingly selling shoddy goods that flood the market (Paton et al, pp. 435-439), ${ }^{4}$ masquerade as being superior to cheaper ones, ${ }^{5-6}$ and lead to dangerous consequences (Smith et al, pp. 406411). Small wonder therefore, that those who promote treatments initially for schizophrenia are now disbelieved and people wait for the independent trials of effectiveness "carried out in "real world" secondary care settings [when] the apparent additional benefits of new treatments are noticeable by their absence' (Scott, pp. 401-403).

Such a trial is reported in this issue by Garety et al (pp. 412-423), not of the usual suspects of antipsychotic drugs, but of a psychological treatment, cognitive-behavioural therapy, that many would like to see as part of the brave new world of acceptable treatments to be engaged with enthusiasm by the disillusioned shopper with schizophrenia. Unfortunately, this too appears to have been oversold. The benefits of some improvement in secondary depressive symptoms noted by the authors are not considered to be sufficient to recommend this treatment for 'routine relapse prevention'. Although this conclusion may be challenged, and indeed a recently published trial in our Journal with somewhat similar results reached different conclusions, ${ }^{7}$ it is clear that 'panacea' and 'treatments for schizophrenia' are words that remain far apart, and Bleuler's rope remains doggedly unravelled.

\section{A full archive}

'The Ninth Report of the Commissioners in Lunacy, to the Lord Chancellor; ordered by. the House of Commons to be printed, May 15, 1855

This Report includes the transactions which occurred during the year 1844. It was presented on the 31st of March, and the public who are interested in lunacy matters, have reason to feel obliged to the commissioners for the promptness of its preparation and publication. The first fact likely to attract the notice of the reader is, that "Miss Mary Fleming is now included with her mother in the license for Warwick House, Chelsea;" and on referring to the list of licensed houses in Appendix A., one cannot fail to be struck with the much larger proportion of female proprietors of licensed houses in the metropolitan district over those in what the commissioners call "the provinces." The proportion being one fourth in the former, and not quite one eleventh in the latter. How it is that the Commissioners in Lunacy, whose powers over the licensed houses in the metropolitan district, are practically without limit, are so much more favorable to female proprietors than county Justices appear to be, we are unable to give any satisfactory reason. After noticing the changes which have taken place in the proprietory of licensed houses, the Commissioners proceed to make some interesting observations on the progress and condition of several of the new county lunatic asylums. The reports on the WARWICK AsYLum are of a favorable nature. The county, however, appears to have greatly overbuilt itself; many wards remaining unoccupied and unfinished. The commissioners mention, that "considerable progress has been made in bringing the land into cultivation;" but they do not state that the land is a tenacious clay of the poorest character."

So begins the first issue of our on-line $\operatorname{archive}^{8}$ available to all subscribers to the Journal and covering a fascinating record of over 160 years. You will come across this again in Trevor Turner's accounts of ' 150 years ago' items (e.g. p. 123 of this volume) as well as Henry Rollin's hardy perennial '100 years ago', but even in this account we can see fascinating glimpses of the growth of gender equality (first beginning in emancipated London), the beginnings of scientific rigour in the Journal (not jumping to conclusions about proprietors), and a preoccupation with hospital beds. On their last point the Commissioners got it wrong but even the cleverest among us sometimes predicts unwisely. Warwick Asylum had not 'overbuilt'; it started out in an area of 72 acres but expanded to 377 with a population of 1600 patients. The land of the Avon valley, as I know from personal experience as a botanist working in the area, is excellent for cultivation and later in the century the patients working in three farms in the grounds provided almost all the food for the hospital's needs. ${ }^{8}$ Now perhaps we could learn from that experience in our management of schizophrenia.

1 Bleuler, E. Dementia Praecox oder Gruppe der Schizophrenien. Franz Deuticke, 1911

2 Johnstone EC, Crow TJ, Frith CD, Husband J, Kreel L. Cerebral ventricular size and cognitive impairment in chronic schizophrenia. Lancet 1976; 2 : 924-6.

3 Berrios G. The history of psychiatric therapies. In Cambridge Textbook of Effective Treatments in Psychiatry (eds P Tyrer, KR Silk), pp. 16-43. Cambridge University Press, 2008.

4 Ito H, Koyama A, Higuchi T. Polypharmacy and excessive dosing: psychiatrists' perceptions of antipsychotic drug prescriptions. Br J Psychiatry 2005; 187: 243-7.

5 Jones PB, Barnes TR, Davies L, Dunn G, Lloyd H, Hayhurst KP, Murray RM, Markwick A, Lewis SW. Randomized controlled trial of effect on quality of life of second- vs first-generation antipsychotic drugs in schizophrenia. Cost Utility of the Latest Antipsychotic Drugs in Schizophrenia Study (CUtLASS 1). Arch Gen Psychiatry 2006; 63: 1079-87.

6 Davies LM, Lewis S, Jones PB, Barnes TRE, Gaughran F, Hayhurst K, Markwick A, Lloyd $\mathrm{H}$ on behalf of the CUtLASS team. Cost-effectiveness of first- $V$. second-generation antipsychotic drugs: results from a randomised controlled trial in schizophrenia responding poorly to previous therapy. Br J Psychiatry 2007; 191: 14-22.

7 Turkington D, Kingdon D, Rathod S, Hammond K, Pelton J, Mehta R. Outcomes of an effectiveness trial of cognitive-behavioural intervention by mental health nurses in schizophrenia. Br J Psychiatry 2006; 189 : $36-40$.

8 Bucknill JC. The Ninth Report of the Commissioners in Lunacy, to the Lord Chancellor: ordered by the House of Commons to be printed, May 15, 1855. Asylum J Ment Sci 1855; 2: 1-16.

9 Cadbury DA, Hawkes JG, Readett RC. A Computer-Mapped Flora: A Study of the County of Warwickshire. Academic Press, 1971. 